\title{
Eva Maria Kohner, 23 February 1929-24 September 2021
}

\author{
Massimo Porta ${ }^{1} \cdot$ Hans-Peter Hammes ${ }^{2}$
}

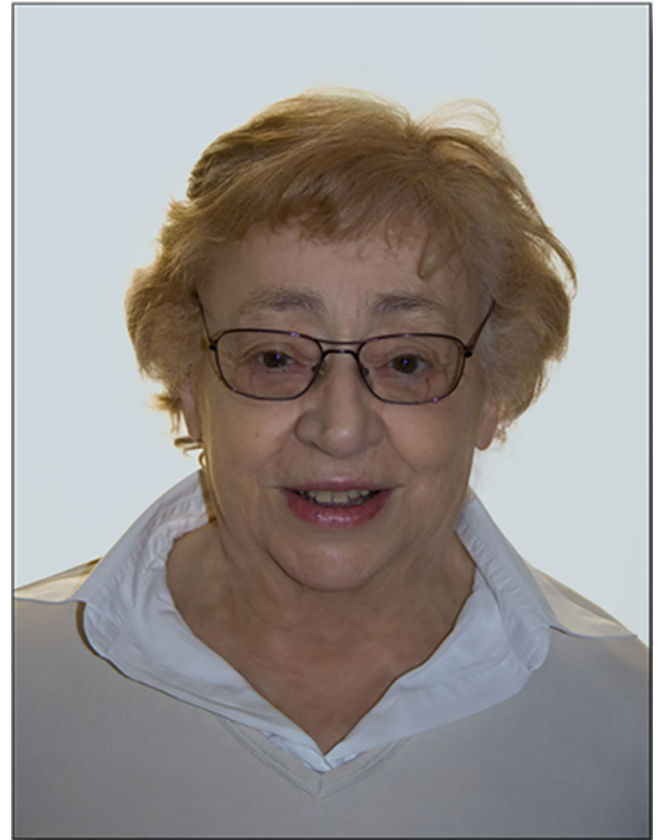

Professor Eva Maria Kohner, Honorary Member of the EASD, passed away on 24 September 2021, aged 92.

Eva M. Kohner used to say that she was not scared when, as a young woman in wartime Budapest, with a yellow star stitched on to her clothes, she naively believed that people could not possibly be gratuitous villains, and that reason could prevail upon prejudice, hatred and fanaticism. Her faith in

Massimo Porta

massimo.porta@unito.it

Department of Clinical Sciences, University of Turin, Turin, Italy

2 Leiter Sektion Endokrinologie 5. Med. Klinik Universitätsmedizin Mannheim, Universität Heidelberg, Heidelberg, Germany humankind helped her survive first the holocaust, then the new regime which made her, born a baroness, an outcast in Soviet-run Hungary.

She fled her country in 1949 and reached Vienna as a refugee. After a short stint selling tickets in a theatre, reinforcing her love of opera, she moved to London and enrolled in nursing school. However, not for her a matron's uniform in a hospital ward. Professor Jerry James tutored her through her medical studies at the Royal Free Hospital, where she graduated in 1959. Eva loved to recount that, when asked at her graduation party about her ambitions, she replied that, as much as she would love to do research, she might have to go into general practice instead. Professor James, consort to the world-famous hepatologist Sheila Sherlock, conceded that Eva's chances of passing an interview for an academic position would always be seriously jeopardised by (not necessarily in this order) being a woman, being a foreigner and speaking with a (strong German) accent. Eventually, Eva moved to Hammersmith Hospital where Professor Colin Dollery, kingmaker of British clinical pharmacologists, was beginning to study retinal circulation with the newly developed technique of fluorescein cineangiography.

Ever determined and consistent, Eva applied herself to the study of diabetic retinopathy, which at the time was an incurable cause of blindness. The only treatment, based upon anecdotal evidence, was hypophysectomy, first by neurosurgery and later by interstitial irradiation. The side effects were possibly worse than the condition it was supposed to treat. Through clinical observation, fluorescein angiography and postmortem retinal digest preparations, Eva's contribution to the understanding of diabetic retinopathy was outstanding; she described the condition's pathophysiology and natural history ('one microaneurysm is not an innocent finding') and pioneered photocoagulation as an effective treatment, 
developing the best possible protocols and silencing sceptics who did not believe in burning the retina to save it.

Eva Kohner was the only female doctor at the Airlie House Symposium of 1968 in Warrenton, VA, USA, where the basis of retinopathy grading was established. Subsequently, she coordinated the British Multicentre Trial of Photocoagulation and contributed to the landmark UK Prospective Diabetes Study (UKPDS). With Massimo Porta, she wrote the Screening for Diabetic Retinopathy in Europe: A Field Guide-Book, which possibly formed the foundation for the ongoing screening programmes in the UK.

Long is the list of degrees and honours bestowed on Eva Kohner: Bachelor of Science (BSc) in Physiology with honours in 1956; Bachelor of Medicine, Bachelor of Surgery (MBBS) in 1959; Membership of the Royal Colleges of Physicians (MRCP) in 1963; Doctor of Medicine (MD) from London University in 1970; Fellow of the Royal College of Physicians (FRCP) in 1977; and Fellow of the Royal College of Ophthalmologists (FRCOphth) in 1991. She became consultant and then Professor of Medical Ophthalmology from 1977 to 1995 at Hammersmith Hospital and Moorfields Eye Hospital, London. In 1990, she co-founded the Eye Complications Study Group of the EASD and was its first president for 4 years. Her special awards are countless, the most prestigious including the Castelli Pedroli Prize and Golgi Lecturer at the EASD symposium 1992, the Banting Lecturer of the British Diabetes Association, 1993, and the Arnall Patz Medal from the Macula Society, 2002. Eva received the Order of the British Empire from Her Majesty the Queen in 1995, and was among the first 30 female members admitted to the Athenaeum club, in 2002. In 2004, Massimo Porta had the pleasure of lauding Eva Kohner when she received her honorary MD at Turin University, Italy. In 1998, Eva was made Honorary Member of the EASD. Together with colleagues from the USA and Europe, she organised an unforgettable EASD/JDRF Oxford workshop on diabetic retinopathy, which brought together many eminent scientists in the field.

Eva Kohner never betrayed her origins. A down-to-earth aristocrat, steel-willed but caring, she could be described as a compassionate Conservative (although she would have rejected this definition). She would speak with, and listen to, her patients, getting to know not only their clinical story but also some of their life's most intimate aspects. With her juniors, she ran hot and cold, reprimanding them (and telling them to their face) if she felt they had been stupid and praising them a few minutes later if they came up with a good idea or interesting observation. Eva was generous with anybody who deserved encouragement, recognition or support. Her strong character emerged most in open discussions at meetings, where her comments and questions will remain memorable. Eva had no time for flattery or nonsense and would speak up when hypotheses or results did not stand up to scrutiny. Sometimes she was proven wrong and would admit it, but most of the time she was not, and there are speakers who still remember the temper of her best years!

Eva Kohner was a knowledgeable woman, curious and present, interested in sports (football especially), arts and music. Her conversation was never dull. She cared for people sincerely. It is a sad turn of destiny that someone who devoted her life to saving other people's sight would end up spending her last years almost blind. Unabated, she continued to work with visual aids and to lead as normal a life as possible until the very end. Mellowed by age and loss of vision, Eva was still trying to write her life story, that of a young Jewish girl who believed that human beings, if they could not be good, should at least behave according to reason and honesty.

Publisher's note Springer Nature remains neutral with regard to jurisdictional claims in published maps and institutional affiliations. 